\title{
AC 2011-1048: CONVERTING AN INTERNAL COMBUSTION ENGINE VEHICLE TO AN ELECTRIC VEHICLE
}

\section{Ali Eydgahi, Eastern Michigan University}

Dr. Eydgahi is an Associate Dean of the College of Technology, Coordinator of PhD in Technology program, and Professor of Engineering Technology at the Eastern Michigan University. Since 1986 and prior to joining Eastern Michigan University, he has been with the State University of New York, Oakland University, Wayne County Community College, Wayne State University, and University of Maryland Eastern Shore. Dr. Eydgahi has received a number of awards including the Dow outstanding Young Faculty Award from American Society for Engineering Education in 1990, the Silver Medal for outstanding contribution from International Conference on Automation in 1995, UNESCO Short-term Fellowship in 1996, and three faculty merit awards from the State University of New York. He is a senior member of IEEE and SME, and a member of ASEE. He is currently serving as Secretary/Treasurer of the ECE Division of ASEE and has served as a regional and chapter chairman of ASEE, SME, and IEEE, as an ASEE Campus Representative, as a Faculty Advisor for National Society of Black Engineers Chapter, as a Counselor for IEEE Student Branch, and as a session chair and a member of scientific and international committees for many international conferences. Dr. Eydgahi has been an active reviewer for a number of IEEE and ASEE and other reputedly international journals and conferences. He has published more than hundred papers in refereed international and national journals and conference proceedings such as ASEE and IEEE.

\section{Mr. Edward Lee Long IV, University of Maryland, Eastern Shore}

Edward Lee Long IV graduated from he University of Maryland Eastern Shore in 2010, with a Bachelors of Science in Engineering. He currently works for Computer Sciences Cooperation as a Flight Safety Engineering Contractor for NASA at Wallops Flight Facility in Wallops Island Virginia. 


\title{
Converting an Internal Combustion Engine Vehicle to an Electric Vehicle
}

\begin{abstract}
Senior students in the Engineering and technology programs are challenged to thoroughly apply their learned technological knowledge and skills toward design and implementation of a challenging engineering product in senior deign or capstone courses. In this paper, a successfully implemented comprehensive design, which utilizes a synergy of competencies gained from undergraduate academic and research experiences with insight to the efforts concerning senior design project is presented.

An electric vehicle is a type of alternative fuel car that utilizes electric motors and motor controllers instead of an internal combustion engine. Power is derived from battery-packs rather than a carbon based fuel. This saves not only money, but has much smaller impact on the environment. One drawback is that current marketed electric vehicles are costly for a consumer to obtain. In this paper, we discuss development of an electric vehicle for a cost that is less than a cost one spends on gas in a single year. The principles and components of electric vehicle systems will be shown and the process of conversion from an internal combustion vehicle to an electric vehicle will be described in detail. This paper demonstrates that creating a running electric vehicle is a financially, environmentally, and intellectually rewarding endeavor.
\end{abstract}

Introduction

Although electric vehicles offer a cost-effective and more environmental-friendly way to travel, their initial cost can drive potential buyers away. Electric cars utilize large battery packs for the energy they use that cost well over tens of thousands dollars for marketed electric vehicles such as the Tesla Roadster. These cars use lithium-ion batteries which tote prices around hundred thousand dollars. Obviously, everyone is looking for ways to make electric vehicles less costly. One way of doing this is to consider converting an internal combustion engine (ICE) vehicle into a new electric one. There are a number of kits on the market that can be utilized to do this conversion, but these kits cost as much as ten thousand dollars in addition to the cost of batteries.

Electric vehicles consist of batteries for energy, an electric motor for power, a controller to control the flow of energy to the motor, and a potentiometer to allow accelerator pedal to provide input to the controller. The vehicle's gasoline engine, exhaust system, gas tank, and clutch assembly will no longer be needed. The manual transmission is bolted to the electric motor and then secured to the vehicle's frame.

A battery box is installed in the vehicle containing 6-volt deep-cycle batteries that are wired in series. The number of batteries is contingent on the size of the vehicle and the type of motor that will be used. However, more batteries make the vehicle heavier but provide a longer range.

A vacuum pump is needed to power the brakes. Voltage and amperage meters are utilized to monitor the state of charge of the battery pack. Finally, there is a need for a charging device to 
charge the DC batteries from an AC source.

In this paper, we describe a method to effectively convert an ICE vehicle to an electrical one with a small budget that results in a vehicle comparable to marketable cars. The main objective of this project was to create a process that can be repeated and used by others. This project is very costeffective and complete conversion including the initial batteries costs less than a quarter of the cost of existing kits.

The following sections introduce the cost comparison of electric vehicles to ones running on gasoline. The numerical modeling for the electric vehicle is presented. It is explained how the results are used to calculate the power needed to start the car, maintain highway speeds, and select the components needed in the conversion. We also present the field data that are obtained from testing the converted vehicle with comparison to that of the model prediction.

\section{Computations}

The cost of operating an electric vehicle can be directly compared to the equivalent operating costs of a gasoline-powered vehicle. A liter of gasoline contains about $8.9 \mathrm{~kW} \cdot \mathrm{h}$ of energy. To calculate the cost of the electrical equivalent of a liter of gasoline, we multiply the utility cost per $\mathrm{kW} \cdot \mathrm{h}$ by 8.9 . Because automotive internal combustion engines are only about $20 \%$ efficient, then at most $20 \%$ of the total energy in that liter of gasoline is used.

Now, let us consider a vehicle powered by an internal combustion engine at $20 \%$ efficiency and $8 \mathrm{~L} / 100 \mathrm{~km}(30 \mathrm{mpg})$. To simply move the vehicle, it requires:

$$
\left(8.9 \mathrm{~kW} \cdot \mathrm{h} \times \frac{8 \mathrm{~L}}{100 \mathrm{~km}}\right) \times 20 \% \text { eff }=\frac{14.2 \mathrm{~kW} \cdot \mathrm{h}}{100 \mathrm{~km}}
$$

At a cost of $\$ 1 / \mathrm{L}(\$ 3.80 / \mathrm{gal})$, the mileage of $8 \mathrm{~L} / 100 \mathrm{~km}(30 \mathrm{mpg})$ equates to:

$$
\frac{\$ 1.00}{L} \times \frac{8 \mathrm{~L}}{100 \mathrm{~km}}=\frac{\$ 8.00}{100 \mathrm{~km}}=\frac{\$ 12.87}{100 \mathrm{mi}}
$$

An electric version of the same car with a charge/discharge efficiency of $81 \%$ and charged at a cost of $\$ 0.10$ per $\mathrm{kW} \cdot \mathrm{h}$ would cost:

$$
\left(\frac{\frac{14.2 \mathrm{~kW} \cdot \mathrm{h}}{100 \mathrm{~km}}}{81 \% \mathrm{eff}}\right) \times \frac{\$ 0.10}{\mathrm{kw} \cdot \mathrm{h}}=\frac{\$ 1.75}{100 \mathrm{~km}}=\frac{\$ 2.82}{100 \mathrm{mi}}
$$

$(14.2 \mathrm{~kW} \cdot \mathrm{h} / 100 \mathrm{~km} / 81 \%$ efficiency $) * \$ 0.10 / \mathrm{kW} \cdot \mathrm{h}=\$ 1.75$ per $100 \mathrm{~km}=\$ 2.82$ per 100 miles

This would equivalent to paying about $\$ 0.22 / \mathrm{L}$ or $\$ 0.83 /$ gal for gasoline.

The most expensive part of an electric vehicle is the batteries. Lead acid batteries have a life of about five years. The cost of replacing the entire battery pack on an electric vehicle is about $\$ 2400$. If we add that to the increased electricity costs for 5 years of use, we get:

$$
\left(\frac{\$ 2.82}{100 m i} \times \frac{10,000 m i}{y r} \times 5 y r\right)+(\$ 2,400)=(\$ 1,410)+(2,400)=\$ 3,810
$$


As electric vehicles have to replace the battery pack every five years, the ICE vehicles have to have regular maintenance and oil changes. For normal use, this cost would be about $\$ 1000$ over the five-year period. Thus, the cost of gasoline vehicle to travel the same distance as electric vehicle would be:

$$
\left(\frac{\$ 12.87}{100 m i} \times \frac{10,000 m i}{y r} \times 5 y r\right)+(\$ 1,000)=(\$ 6,435)+(\$ 1,000)=\$ 7435
$$

This is almost double the operating costs of an electric vehicle.

\section{Model Development}

This project began with a 1992 manual Chevy S-10 pickup as shown in figure 1. This vehicle was chosen as its bed gave us an easy location to store batteries, its manual transmission allows for an easier adaptation to an electric motor, and it was readily available.

We calculated the power required to reach a number of different top speeds as well as the range associated with them based on the weight of the truck, weight of the proposed electrical components, dimensions, and the desired range.

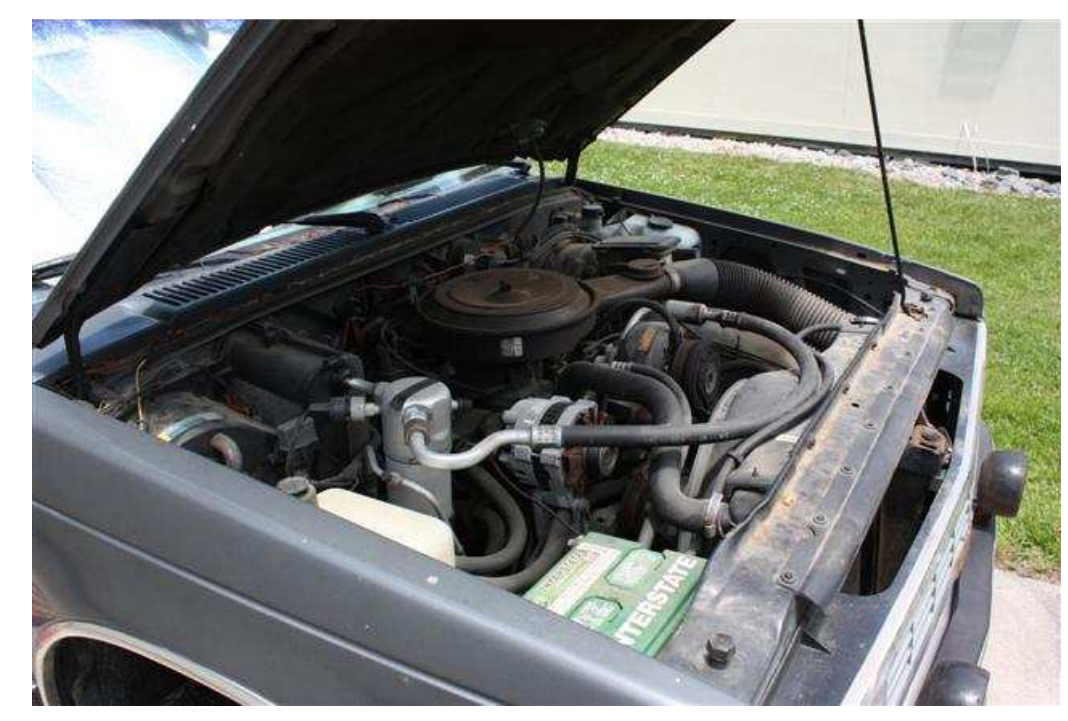

Figure 1: The Manual Chevy S-10pPickup

First, to determine the power needed to reach the targeted highway speeds, the forces acting on the moving truck were considered. The truck dimensions and weight were determined after the conversion and are shown in table 1. 
Table 1: The Dimensions and Weight of the Chevy S-10pPickup

\begin{tabular}{|c|c|c|c|c|}
\hline Overall Length & length $_{\mathrm{car}}$ & $=$ & 4648.2 & $\mathrm{~mm}$ \\
\hline Overall Width & width $_{\text {car }}$ & $=$ & 1523.6 & $\mathrm{~mm}$ \\
\hline Overall Height & height $_{\mathrm{car}}$ & $=$ & 1338.9 & $\mathrm{~mm}$ \\
\hline Length X Width & area $_{\text {car }}$ & $=$ & 7.089 & $\mathrm{~m}^{2}$ \\
\hline Wheelbase & wheelbase & $=$ & 2743.2 & $\mathrm{~mm}$ \\
\hline Curb Weight & $\begin{array}{c}\text { curbweigh } \\
\mathrm{t}_{\text {car }}\end{array}$ & $=$ & 1487 & $\mathrm{~kg}$ \\
\hline Gross Car Weight & $\begin{array}{c}\text { grossweig } \\
\mathrm{ht}_{\mathrm{car}}\end{array}$ & $=$ & 1124 & $\mathrm{~kg}$ \\
\hline \multirow{2}{*}{$\begin{array}{l}\text { Weight of Battery Pack } \\
\text { (24 Lead Acid Batteries) }\end{array}$} & \multirow{2}{*}{$\begin{array}{c}\text { weight }_{\text {batter }} \\
\mathrm{y}\end{array}$} & $=$ & \multicolumn{2}{|c|}{$24 \times 20$} \\
\hline & & $=$ & 480 & $\mathrm{~kg}$ \\
\hline Weight of Motor & weight $_{\text {motor }}$ & $=$ & 58 & $\mathrm{~kg}$ \\
\hline $\begin{array}{l}\text { Weight of ICE } \\
\text { Motor+exhaust }\end{array}$ & $\begin{array}{l}\text { weight }_{\text {icem }} \\
\text { otor }\end{array}$ & $=$ & 363 & $\mathrm{~kg}$ \\
\hline \multirow[t]{2}{*}{ New Weight of Car } & \multirow[t]{2}{*}{ weight $_{\text {car }}$} & $=$ & \multicolumn{2}{|c|}{$\begin{array}{c}\text { curbweight }_{\text {car }}-\text { weight }_{\text {icemotor }}+ \\
\text { weight }_{\text {battery }}+\text { weight }_{\text {motor }}\end{array}$} \\
\hline & & $=$ & 1662 & $\mathrm{~kg}$ \\
\hline Differential Gear Ratio & AR & $=$ & 3.25 & unit-less \\
\hline Wheel Radius & wheel $_{\mathrm{rad}}$ & $=$ & 330 & $\mathrm{~mm}$ \\
\hline
\end{tabular}

The data in table 1 were used to determine the truck's drag force in the air as shown in table 2.

Table 2: The Chevy S-10pPickup Drag Force

\begin{tabular}{|c|c|c|c|c|}
\hline Coefficient of Drag & $\mathrm{Cd}$ & $=$ & 0.34 & \\
\hline Density of Air & $\mathrm{P}_{\text {air }}$ & $=$ & 1.2 & $\mathrm{~kg} /\left(\mathrm{m}^{3}\right)$ \\
\hline Cross Sectional Area & $\mathrm{A}_{\mathrm{c}}$ & $=$ & height $_{\mathrm{car}} \times$ width $_{\mathrm{car}}$ \\
\cline { 3 - 5 } & & $=$ & 2039.9 & $\mathrm{~m}^{2}$ \\
\hline Drag Force & $\mathrm{F}_{\mathrm{d}}\left(\mathrm{v}_{\mathrm{ca}}\right)$ & $=$ & $1 / 2 \times \mathrm{P}_{\text {air }} \times \mathrm{A}_{\mathrm{c}} \times \mathrm{Cd} \mathrm{x} \mathrm{\textrm {car } ^ { 2 }}$ \\
\cline { 3 - 5 } & & $=$ & 231.503 & $\mathrm{~N}$ \\
\hline
\end{tabular}

Then, the rolling resistance force and internal resistance force were calculated as demonstrated in table 3 . 
Table3: The Rolling Resistance and Internal Resistance Forces

\begin{tabular}{|c|c|c|c|c|}
\hline $\begin{array}{c}\text { Coefficient of rolling } \\
\text { resistance }\end{array}$ & $\mu_{\mathrm{rr}}$ & $=$ & \multicolumn{2}{|c|}{0.010} \\
\hline Rolling Resistance Force & $\mathrm{F}_{\mathrm{rr}}$ & $=$ & $\mu_{\mathrm{rr}} \times$ weight $_{\mathrm{car}} \times 9.81 \mathrm{~m} /\left(\mathrm{s}^{2}\right)$ \\
\cline { 2 - 5 } & $=$ & 163.422 & $\mathrm{~N}$ \\
\hline $0-60$ mph time & $\mathrm{t}_{60}$ & $=$ & 12 & $\mathrm{~s}$ \\
\hline Acceleration & acc & $=$ & \multicolumn{2}{|c|}{$(60 \mathrm{mph}) / \mathrm{t}_{60}$} \\
\cline { 3 - 5 } & & $=$ & 2.235 & $\left.\mathrm{~m} / \mathrm{s}^{2}\right)$ \\
\hline Sum of Internal Forces & $\mathrm{J}_{\mathrm{car}}$ & $=$ & 0.041 & $\mathrm{~N} \mathrm{x} \mathrm{m}$ \\
\hline $0-60 \mathrm{mph}$ time & $\mathrm{F}_{\mathrm{I}}$ & $=$ & \multicolumn{2}{|c|}{ acc $\mathrm{x}$ weight } \\
& & $=$ & 3714.570 & $\mathrm{~N}$ \\
\hline
\end{tabular}

Next, we obtained the maximum starting force and the force to maintain constant speed at our targeted top speed of $65 \mathrm{mph}$ as shown in table 4.

Table 4: The Maximum Starting Force and the Force to Maintain Constant Speed at $65 \mathrm{mpg}$

\begin{tabular}{|c|c|c|c|c|}
\hline \multirow[t]{2}{*}{ Total Force at Starting } & \multirow[t]{2}{*}{$\mathbf{F}_{\text {start }}$} & $=$ & \multicolumn{2}{|c|}{$F_{I}+F_{r r}$} \\
\hline & & $=$ & 3877.992 & $\mathrm{~N}$ \\
\hline \multirow[t]{2}{*}{ Total Force at Top Speed } & $\mathrm{F}_{\text {top }}$ & $=$ & \multicolumn{2}{|c|}{$\mathrm{F}_{\mathrm{rr}}+\mathrm{F}_{\mathrm{d}}(65 \mathrm{mph})$} \\
\hline & & $=$ & 775.076 & $\mathrm{~N}$ \\
\hline \multirow[t]{2}{*}{$\begin{array}{c}\text { Speed at Wheel to Speed } \\
\text { at Shaft }\end{array}$} & $\begin{array}{c}\text { Motor } \\
\text { arpeed }\end{array}$ & $=$ & \multicolumn{2}{|c|}{$\mathrm{v}_{\mathrm{car}} /$ diamwheel $_{\mathrm{cir}} \times \mathrm{AR}$} \\
\hline & & $=$ & $2.516 \times 10^{3}$ & $\mathrm{rpm}$ \\
\hline
\end{tabular}

\section{Design}

The conversion process is shown in figure 2. The gasoline engine, muffler, catalytic converter, tailpipe, and gas tank were removed. The clutch assembly was removed but the existing manual transmission was left in place, although the clutch is no longer needed. A new DC electric motor was bolted to the transmission with an adapter plate.

An electric controller was added to control the DC motor. The controller takes power from the batteries and delivers it to the motor. The accelerator pedal is hooked to a potentiometer that provides the controller with the signal that indicates the amount of power to be delivered. The controller can deliver zero power when the car is stopped, full power when the accelerator pedal is push all the way down, or any amount between. 

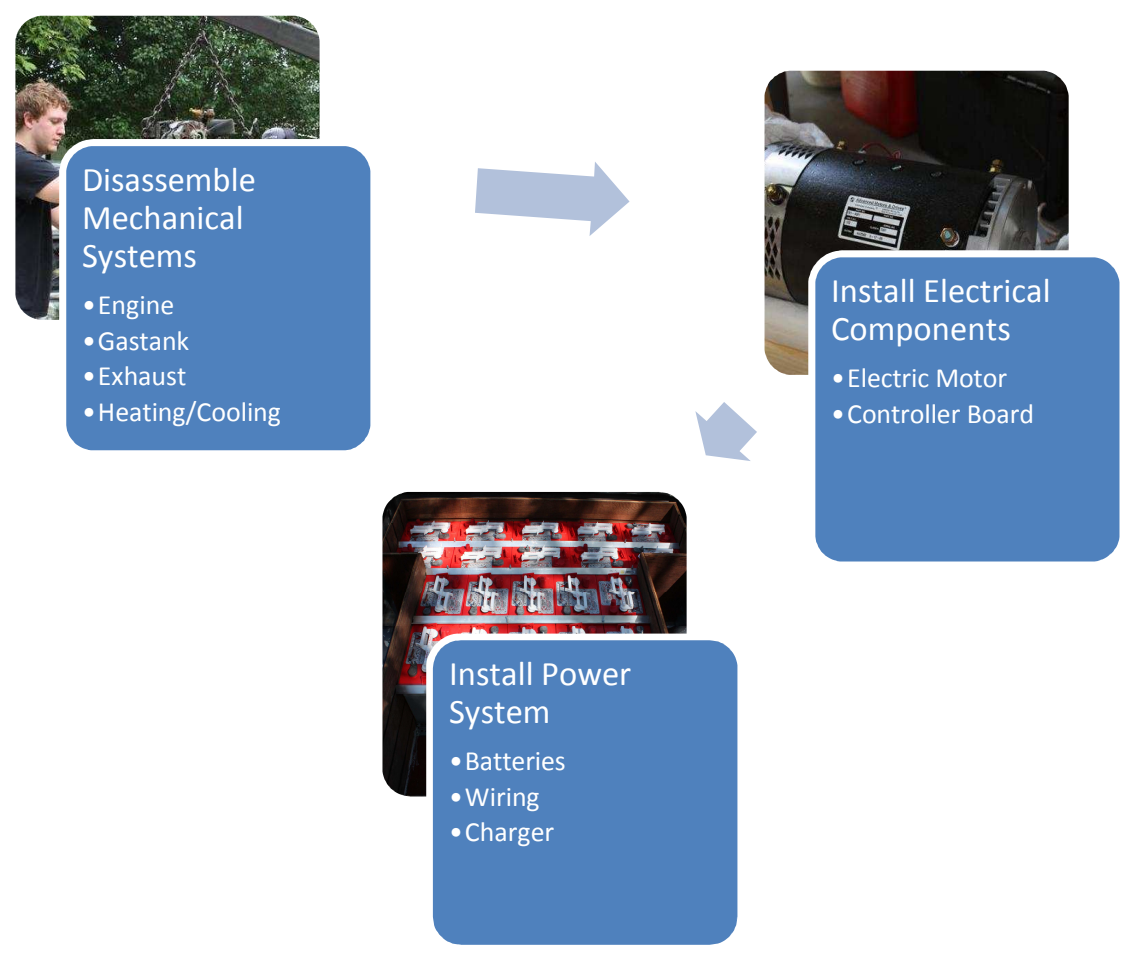

Figure 2: The Proposed Conversion Process

A battery box is installed in the truck containing twenty four 6-V batteries. An electric heater was added and a vacuum pump is used for the power brakes. A charger was added so that the batteries could be recharged from any 110 -volt or 220 -volt wall outlet. The gas gauge in the instrument panel was replaced with a voltmeter and an ammeter.

\section{Components of the Design}

The raw power calculations provided the information needed to choose an appropriate electric motor as well as the number of batteries that were required to reach an adequate range of operation. We then began our search for components.

We decided on a single shafted Advanced DC electric motor with $72-144 \mathrm{~V}$ and $18-30 \mathrm{HP}$ as shown in figure 3. This motor would allow a top speed of $70 \mathrm{mph}$ with twenty four 6-volt batteries and an average range of 100 miles. The rest of the components were chosen as ones that would work with the motor and for a low price. The full cost of components were about $\$ 3694$, but after selling the ICE motor and exhaust, that no longer were needed, the cost went down to $\$ 2479$. 


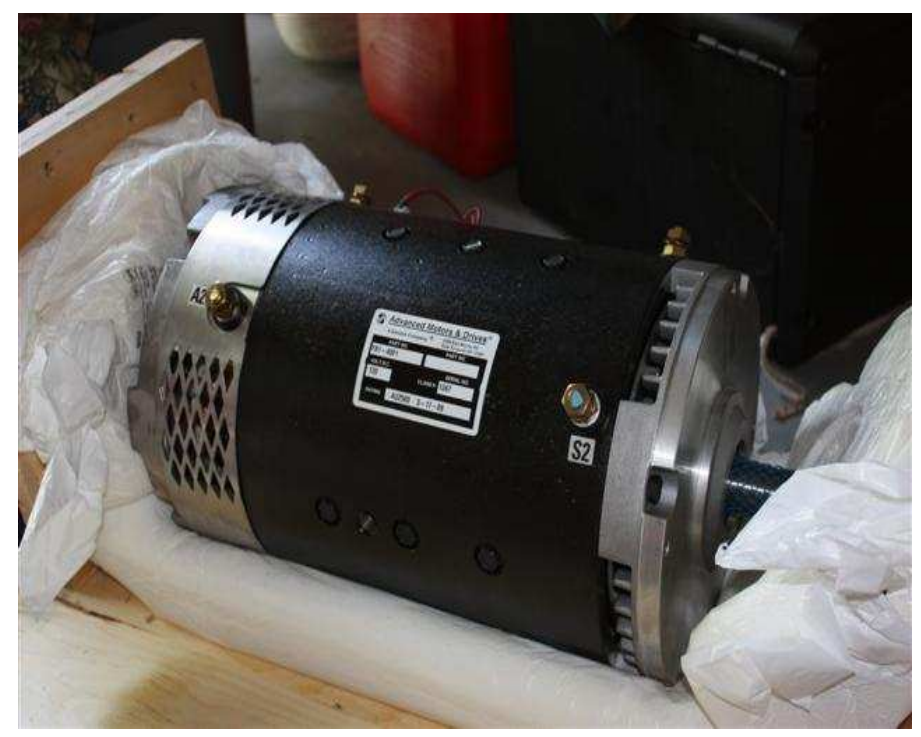

Figure 3: Advanced DC Electric Motor

The selected controller was the $1231 \mathrm{C}-8601$ Curtis Controller as shown in figure 4. This controller was selected because it can handle our desired 144-V DC. It has a 500-amp max and uses the selected $0-5 \mathrm{kohm}$ potentiometer. It is also a fairly well known and widely used model that ensures proper value and electric vehicle support.

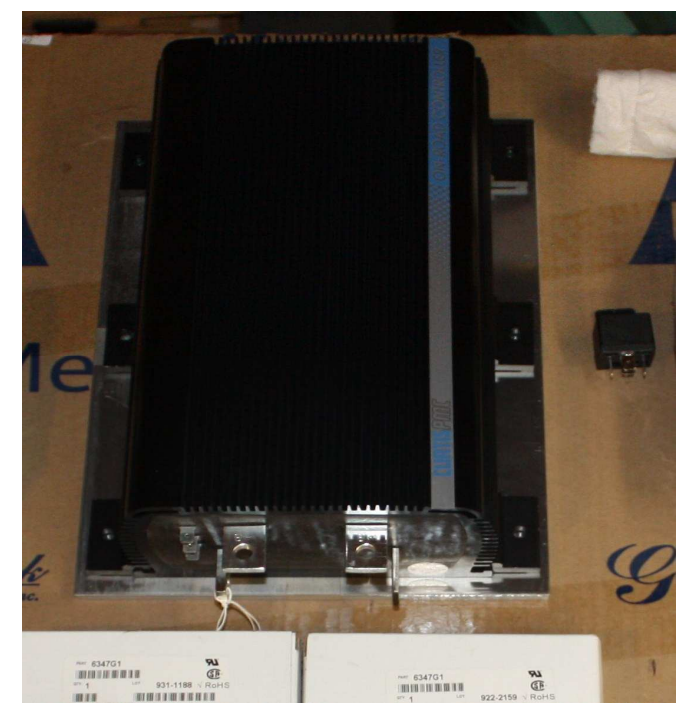

Figure 4: Curtis Controller

We used two contactors that were able to handle the current flowing from the battery packs. The contactors act as relays, keeping the 144-V away from the board and electronics until it is needed for moving. The primary contactor closes as soon as the key is turned-on, however, the secondary contactor only closes when the pedal is pressed. Figure 5 represents contactor used in the design. 


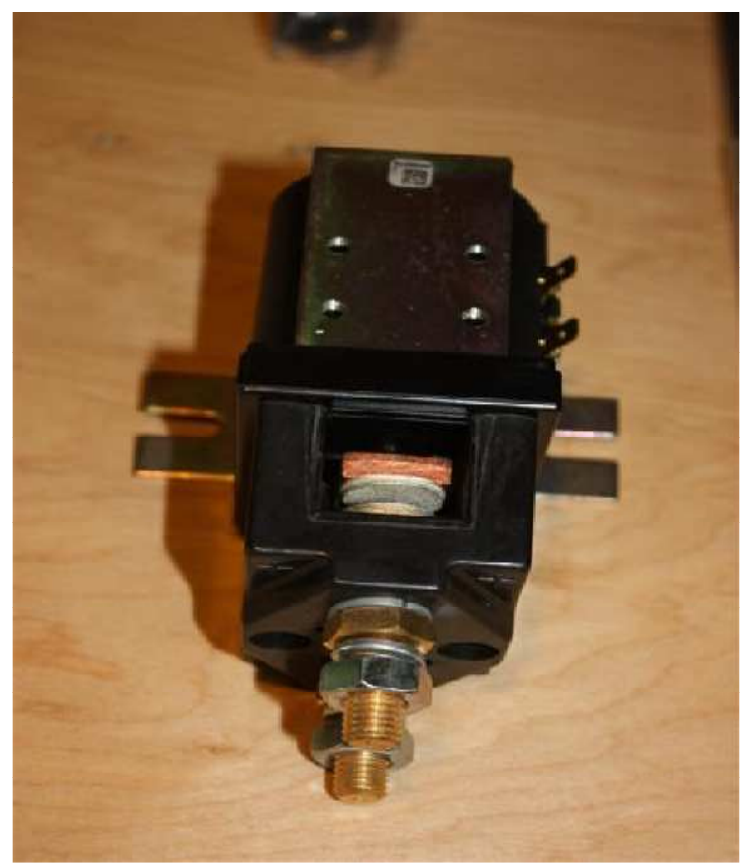

Figure 5: Contactor Used in the Design

The DC charger selected is a "smart" charger that is designed to extend the batteries life by using pre-programmed algorithms to control the charging rate. It can also accept both $110-\mathrm{V}$ AC and $220-\mathrm{V}$ AC that make it quite versatile.

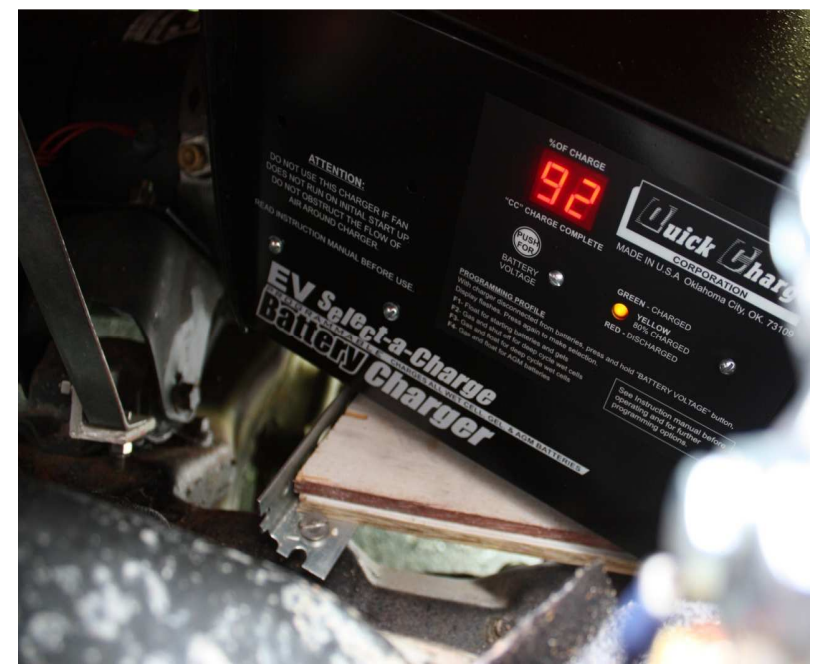

Figure 6: The DC Charger

Next was the disassembling part of this project. We removed the exhaust system, engine, clutch and transmission, condenser and radiator, gas tank, and the bed of the pickup truck.

With the transmission removed, it was easy to attach the new electric motor to the drive system 
using a manufactured aluminum adapter plate as shown in figure 7 . The $1 / 2$ inch aluminum plat provides plenty of strength and a good and strong connection. The new electric motortransmission assembly was reinstalled along with the drive shaft and everything was securely attached to the truck's frame.

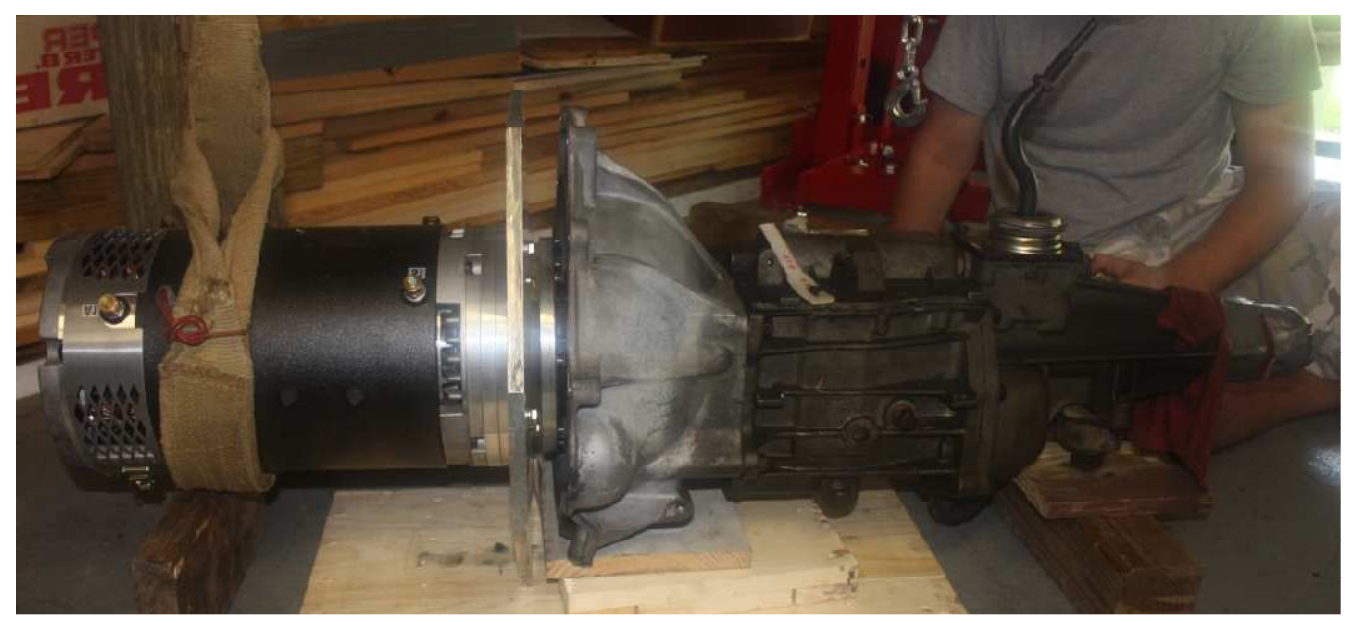

Figure 7: Electric Motor-Transmission Assembly

An electric vacuum pump was installed so that the existing power brakes could be used. It is installed to the 12-volt system so we were able to test and confirm that it was working.

The heater was replaced with a ceramic heater core as it was to be powered via the new electric circuitry on 144-V DC.

The controller and its circuit were the next task completed as represented in figure 8. This circuit consists of a potentiometer, contactors, fuses, a DC-DC converter for converting $144-\mathrm{V}$ to $12-\mathrm{V}$, a shunt for current measurement, and safety disconnects for connectors leaving the board. This circuit allows the power to be completely cut off from all of the electrical components on the 144-volt system whenever the key is off and when the accelerator is depressed.

These components were installed on a board that is mounted above the motor in the engine compartment. 


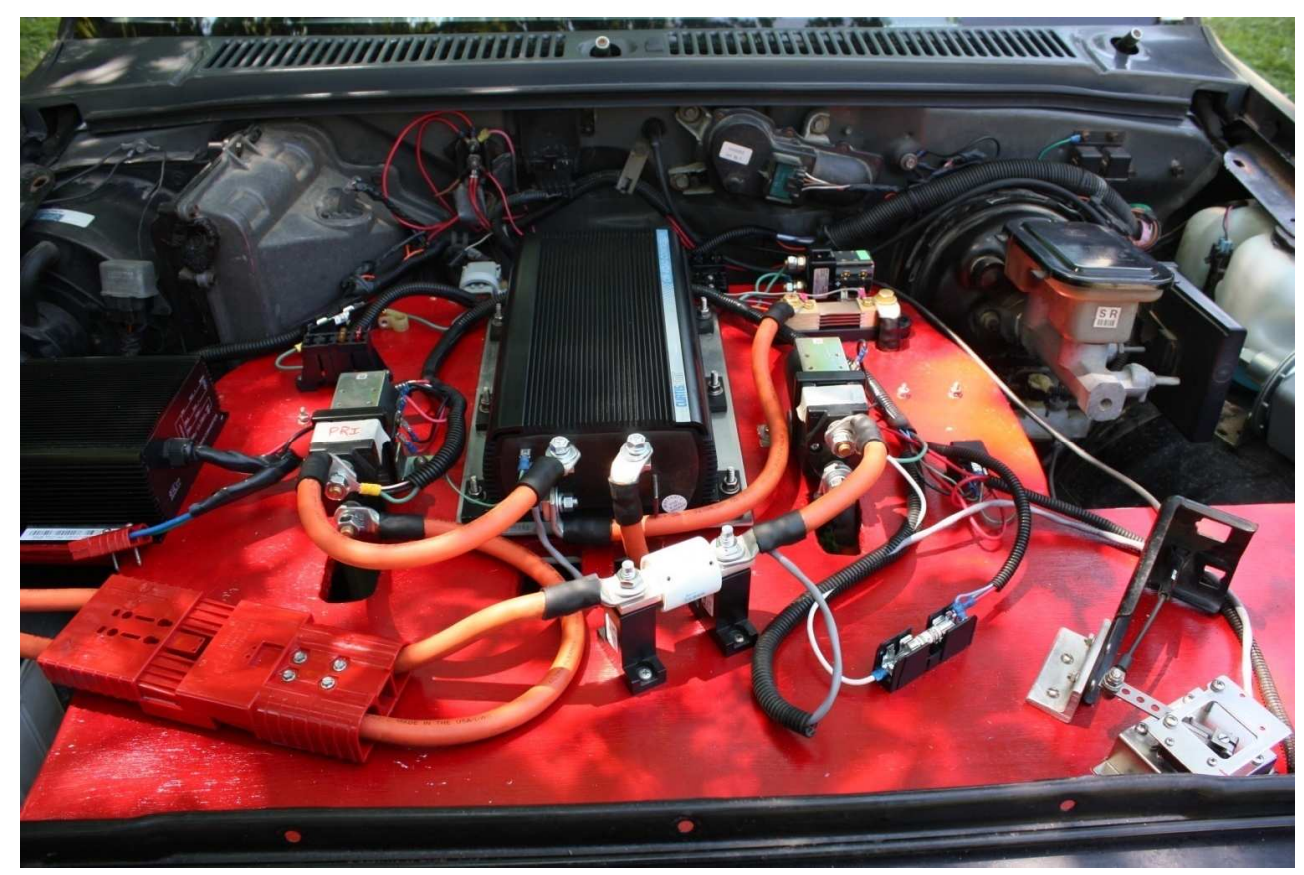

Figure 8: Controller and its circuits

Two new instruments, a voltmeter gauge and an ammeter gauge, as shown in figure 9 were installed in the truck. The voltmeter effectively serves as the gas gauge showing the voltage level of the battery bank. The ammeter shows the amount of current drawn from the batteries. It provides an indication of how quickly the batteries are being drained.

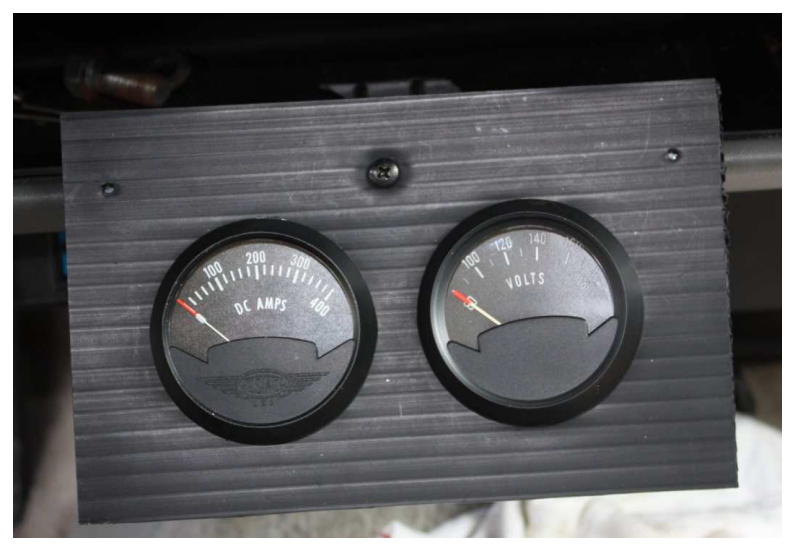

Figure 9: Voltmeter and Ammeter Gauges

The battery box includes twenty four batteries in four rows of five and two rows of two as shown in figure 10. The box keeps the batteries from moving around and from falling out in the case of an accident. This also serves to keep the batteries operational in various weather conditions. Once the batteries were installed, 2-gauge wire was used to connect them in series to form the 144-V needed to power the electric vehicle. 


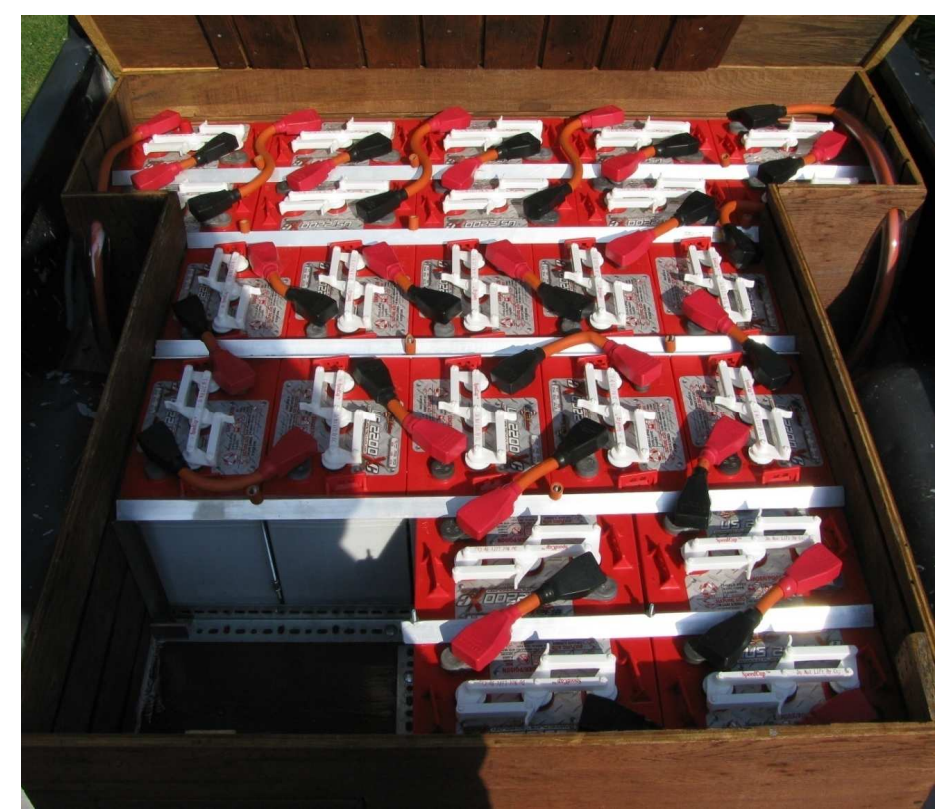

Figure 10: The Battery Compartment

The battery box in the bed was connected to contactors on the controller board by two wires. These two wires serve as the only connection between the batteries and the motor controller. The controller board's $144-\mathrm{V}$ connections were completed by using the $2 / 0$ gauge wire.

The DC charger needed to charge the $144-\mathrm{V}$ battery bank was installed under the truck's hood below the controller board. This gives it plenty of ventilation to prevent overheating. The final assembly is shown in figure 11.

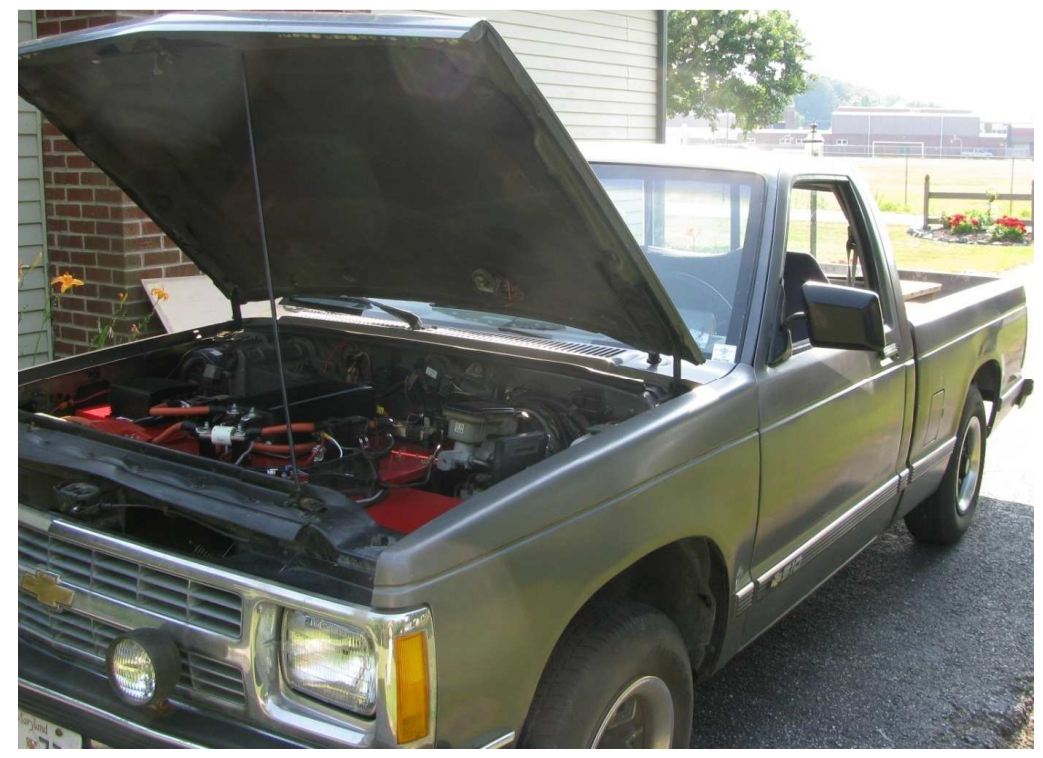

Figure 11: The Designed Electric Truck 


\section{Testing}

The main goals for this project besides the obvious goal for cost were to have an adequate range for driving and a possible acceleration time from 0 to $60 \mathrm{mph}$ of about 15 seconds.

Over a course of about 14 tests, we estimated the range for $80 \%$ of the total charge. The results can be observed in the table 5 .

Table 5: The Estimated Range for $80 \%$ of the Total Charge

\begin{tabular}{|c|c|c|c|c|c|c|}
\hline $\begin{array}{c}\text { Starting } \\
\text { Mileage }\end{array}$ & $\begin{array}{c}\text { Ending } \\
\text { Mileage }\end{array}$ & $\begin{array}{c}\text { Starting } \\
\text { Charge }\end{array}$ & $\begin{array}{c}\text { Ending } \\
\text { Charge }\end{array}$ & $\begin{array}{c}\text { Total } \\
\text { Mileage }\end{array}$ & $\begin{array}{c}\text { \% of charge } \\
\text { used }\end{array}$ & $\begin{array}{c}\text { Estimated 80\% } \\
\text { range }\end{array}$ \\
\hline 0 & 15.7 & 152.8 & 150.5 & 15.7 & 13.94 & 90.1 \\
\hline 15.8 & 42.8 & 150.1 & 146.1 & 27 & 24.24 & 89.1 \\
\hline 0 & 28.6 & 152.7 & 148.2 & 28.6 & 27.27 & 83.89 \\
\hline 0 & 35.1 & 153 & 148 & 35.1 & 30.3 & 92.66 \\
\hline 35.1 & 65.3 & 145.5 & 141.2 & 30.2 & 26.06 & 92.71 \\
\hline 0 & 42.2 & 152.9 & 146.8 & 42.2 & 36.97 & 91.32 \\
\hline 0 & 40.9 & 152.8 & 146.9 & 40.9 & 35.76 & 91.51 \\
\hline 0 & 29.3 & 152.8 & 148.5 & 29.3 & 26.06 & 89.94 \\
\hline 29.3 & 68 & 147.6 & 142.4 & 38.7 & 31.52 & 98.24 \\
\hline 68 & 85.8 & 142.4 & 140 & 17.8 & 14.55 & 97.9 \\
\hline 0 & 50.6 & 152.9 & 145.5 & 50.6 & 44.85 & 90.26 \\
\hline 0 & 68 & 152.8 & 143 & 68 & 59.39 & 91.59 \\
\hline 0 & 30.2 & 152.8 & 148.3 & 30.2 & 27.27 & 88.59 \\
\hline 30.2 & 88.7 & 148.3 & 140.3 & 58.5 & 48.48 & 96.53 \\
\hline & & Average: & & & 91.74 \\
\hline
\end{tabular}

\section{Results}

As shown in table 5, the range averages to over 90 miles for an $80 \%$ state of charge. We were able to accomplish the acceleration time from 0 to $60 \mathrm{mph}$ for about 15 seconds. However, under normal driving conditions it is safer and far less power is used if we accelerate slowly for a period of about 25 seconds.

For a complete charge time from about $20 \%$ existing charge, the vehicle takes about 6 hours to charge from a $110-\mathrm{V}$ outlet and only about 3 hours when a $220-\mathrm{V}$ outlet is used. The results are summarized in table 6 . 
Table 6: The Charge Time Chart

\begin{tabular}{|c|c|c|c|}
\hline Range & & 90 & miles \\
\hline 0-to-60 mph time & & 15 & seconds \\
\hline Charging time & 110 & 6 & hours \\
\cline { 2 - 4 } & 220 & 3 & hours \\
\hline
\end{tabular}

This confirms the estimated values that were calculated from our earlier model. The range varied some with each testing as the driving conditions changed. Using the break more heavily or being heavy-footed on the accelerator petal could be potential reasons for some of the range discrepancies. It should also be noted that the batteries were new. This means that they will not be able to provide the truck its maximum range until they have experienced more than 150 charge/discharge cycles. Considering the measured 90-mile range, it is estimated that a range of over 100 miles per charge can be obtained.

\section{Conclusions}

Design and implementation of an electric vehicle were presented that is capable of traveling almost 100 miles in a single charge while it cost less than a quarter of the cost of an electric conversion kit and $97 \%$ less than cost of some commercial models. A charge that costs only a fifth of a tank of gas and could potentially be free with alternative sources of energy like solar or wind. Using an older vehicle actually allowed us to make some money on scrap parts. Also, by calculating the power we needed to reach a reasonable speed, we were able to save money on components too.

The undergraduate students have difficulties making decisions based on their knowledge, information gathered, budget, and time limitations. The education experiences were enormous for the student involved in this project. Implementation of this electric truck was accomplished through a few hours each day on weekends for a year by a senior electrical engineering student. The student had great collaboration and interaction with his grandfather who acted as his project mentor on the field. It was a fun and challenging project, which provided him extensive educational experience both socially and technically by interacting and consulting his mentor and various vendors.

It is hoped that such a cost-effective conversion project would inspire other students and educators to pursue development of similar projects not only for saving money but also to gain an educational experience that would make the live a little greener. 


\section{References}

1. Leitman, S. and Brant, B.; Build Your Own Electric Vehicle, McGraw Hill, 1993.

2. Johnson, C.; "Physics In an Automotive Engine," http://mb-soft.com/public2/engine.html

3. Carr, B.; "Are Electric Cars the Answer to the Growing Environmental Problems?", March 30th, 2007.

http://www.dailyfueleconomytip.com/gas-saving-innovations/are-electric-cars-theanswer-to-the-growing-environmental-problems/

4. Admin.; “The Energy Revolution: Could America get left behind?”, September 27, 2008. http://www.onelectriccars.com/the-energy-revolution-could-america-get-left-behind/133/ 